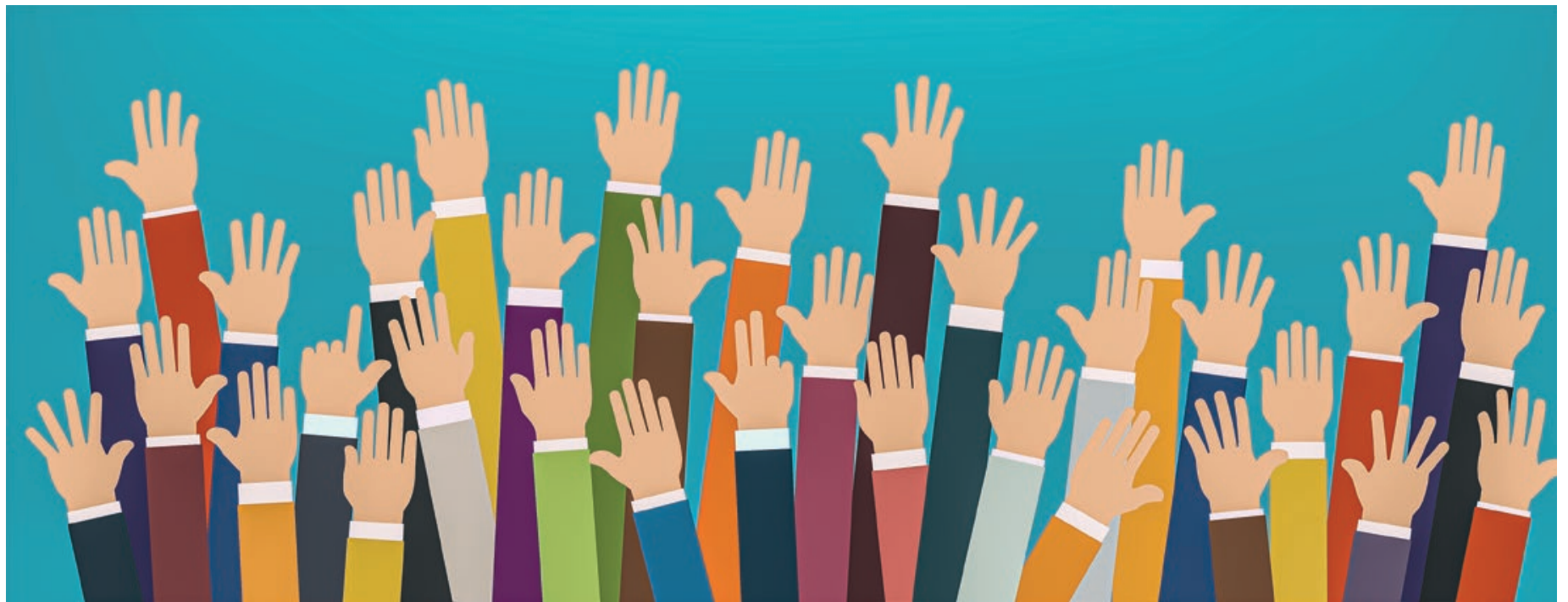

\title{
Ersatzwahl: Lateinischsprachige Schweiz im FMH-Zentralvorstand
}

\section{Yvonne Gilli}

Dr. med., Präsidentin FMH

Verschiedene Mitgliedorganisationen haben uns aufgefordert, die Ersatzwahl vorzuziehen und eine ausserordentliche Ärztekammer einzuberufen. Mit dem ausserterminlichen Rücktritt von Michel Matter ist der Sitz der lateinischsprachigen Schweiz ab dem 31. Januar 2022 vakant. Die ausserordentliche Ärztekammersitzung findet am Nachmittag des 3. März 2022 virtuell statt.

Bitte beachten Sie, dass die von der Ärztekammer zu wählenden Personen gemäss Art. 22 der Statuten der FMH mit Erreichung ihres 68. Altersjahres aus dem Amt ausscheiden, sofern die Ärztekammer im Einzelfall keine Ausnahme beschliesst. Neben den statutarischen Voraussetzungen (Facharzt-Titel und FMH-Mitgliedschaft) sind unter anderem politische und standespolitische Erfahrung, Führungskompetenz und Sprachkompetenzen Voraussetzungen für die Kandidatur.
Die Kandidaturen mit Beilagen benötigen wir bis spätestens am 1. Februar 2022 per E-Mail an direction[at]fmh.ch. Später eintreffende Angaben können nicht mehr mit der regulären Einladung versandt werden. Ein Anforderungsprofil der Kandidatinnen und Kandidaten für den Zentralvorstand (ZV) sowie das Formular zur Publikation in der SÄZ erhalten Sie ebenfalls unter der E-Mail-Adresse direction[at] fmh.ch. Für Ihre Fragen zur Ersatzwahl stehen wir gerne zur Verfügung.

Bildnachweis

Ramcreativ | Dreamstime.com 